\title{
Erratum to: The contribution of bank regulation and fair value accounting to procyclical leverage
}

\author{
Amir Amel-Zadeh ${ }^{1}$ • Mary E. Barth ${ }^{2}$.
}

Wayne R. Landsman ${ }^{3}$

Published online: 25 July 2017

(C) Springer Science+Business Media, LLC 2017

\section{Erratum to: Rev Account Stud \\ DOI 10.1007/s11142-017-9410-6}

The original version of this article unfortunately contained a formatting mistake. In Table 7 Panel D, the columns have moved resulting to misalignment with the column headings.

With this, the corrected Table 7 is hereby published.

Amir Amel-Zadeh

amir.amelzadeh@sbs.ox.ac.uk

Mary E. Barth

mbarth@stanford.edu

Wayne R. Landsman

Wayne_Landsman@unc.edu

1 Saïd Business School, University of Oxford, Park End Street, Oxford OX1 1HP, UK

2 Graduate School of Business, Stanford University, Stanford, CA, USA

3 Kenan-Flagler Business School, University of North Carolina, Chapel Hill, NC, USA 


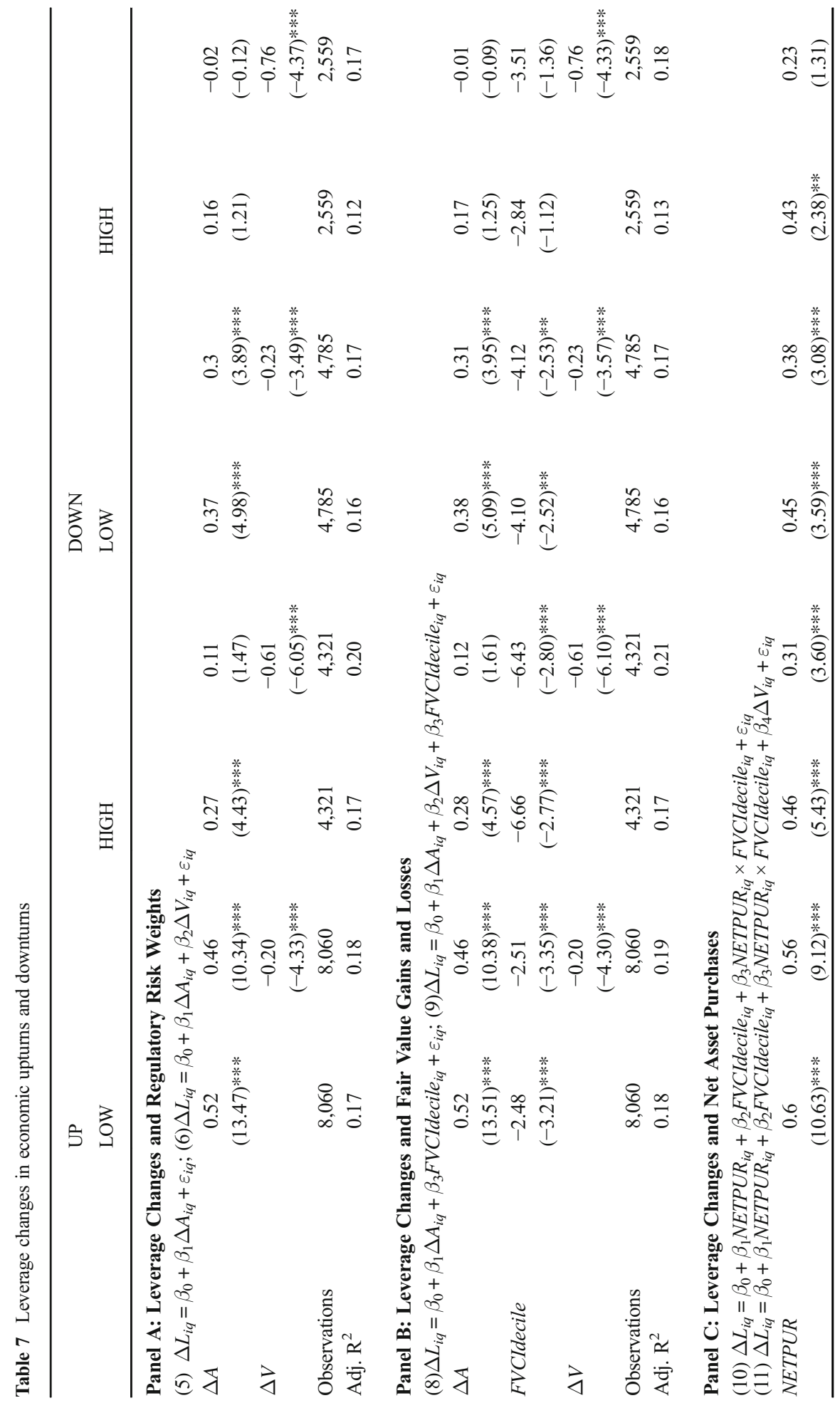




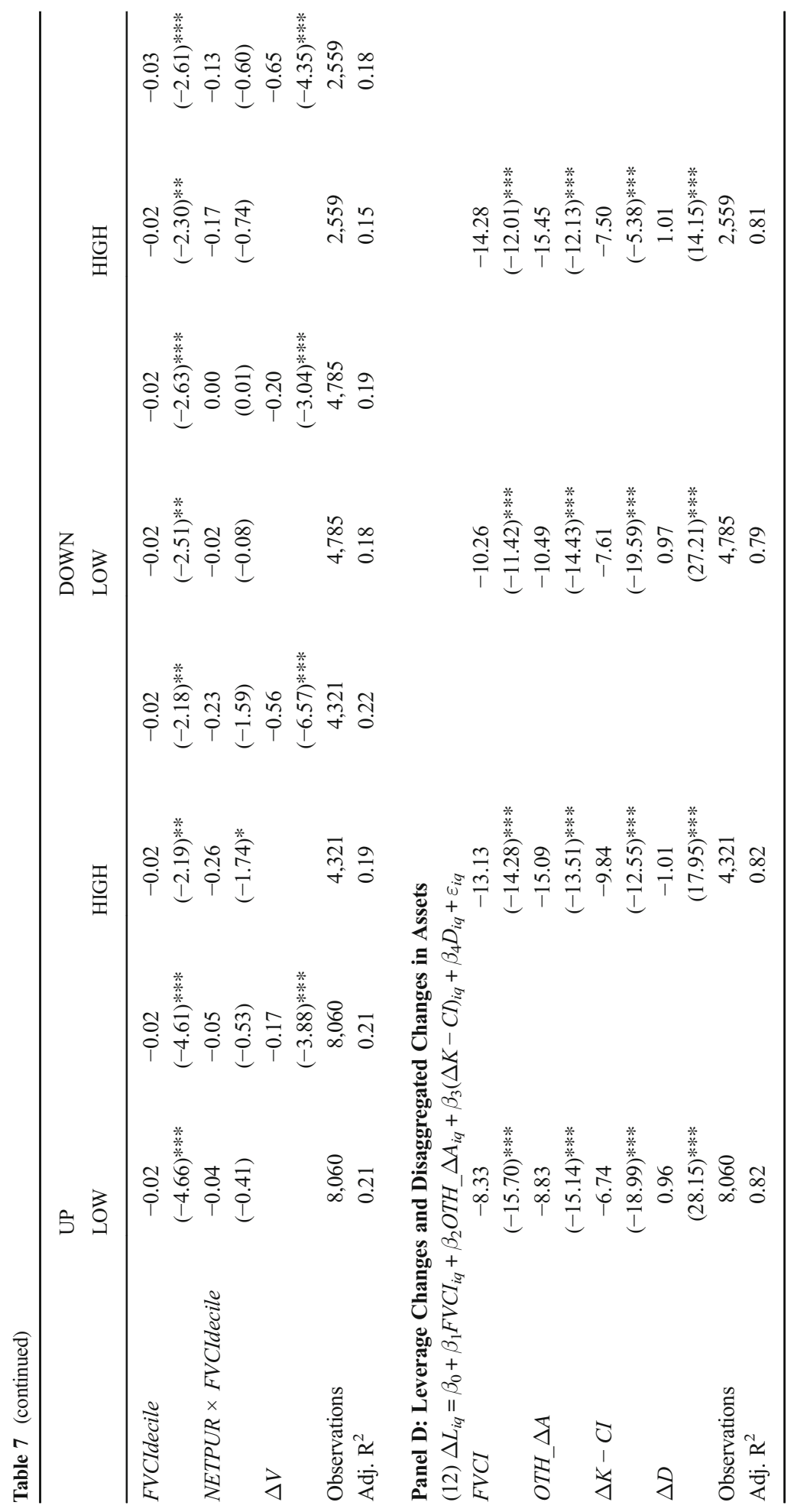

